\title{
SAC and SAC-CI Calculations of Excitation and Circular Dichroism Spectra of Straight-Chain and Cyclic Dichalcogens
}

\author{
Junji Seino, Yasushi Honda, and Masahiko Hada* \\ Department of Chemistry, Graduate School of Science, Tokyo Metropolitan University, 1-1 Minami-Osawa, \\ Hachioji-shi, Tokyo 192-0397, Japan
}

\author{
Hiroshi Nakatsuji \\ Department of Synthetic Chemistry and Biological Chemistry, Graduate School of Engineering, \\ Kyoto University, Nishikyo-ku, Kyoto 615-8510, Japan
}

Received: May 4, 2006; In Final Form: June 14, 2006

\begin{abstract}
Accurate quantum-chemical calculations of the excitation energies and the rotatory strengths of dichalcogens $\mathrm{R}-\mathrm{Ch}-\mathrm{Ch}-\mathrm{R}(\mathrm{Ch}=\mathrm{S}, \mathrm{Se}, \mathrm{Te})$ were carried out with the symmetry adapted cluster (SAC) and $\mathrm{SAC}-$ configuration interaction $(\mathrm{CI})$ methods. A series of straight-chain molecules (dihydrogen dichalcogenide, dimethyl dichalcogenide, and (+)-bis(2-methylbutyl) dichalcogenide) and one cyclic molecule $(2,3-(R, R)-$ dichalcogenadecalin) were adopted for comparative analysis. The calculated excitation and circular dichroism (CD) spectra were in good agreement with experimental ones (Laur, P. H. A. In Proceedings of the Third International Symposium on Organic Selenium and Tellurium Compounds; Cagniant, D., Kirsch, G., Eds.; Universite de Metz: Metz, 1979; pp 219-299) within $0.3 \mathrm{eV}$. The fitting CD spectra also reasonably reproduced the experimental ones. In all the molecules adopted, the first and second lowest bands were assigned to the $\mathrm{n}-\sigma^{*}(\mathrm{Ch}-\mathrm{Ch})$ transition and the third and fourth lowest bands to the $\mathrm{n}-\sigma^{*}(\mathrm{Ch}-\mathrm{R})$ transition. The first and second lowest bands apparently depended on the $\mathrm{R}-\mathrm{Ch}-\mathrm{Ch}-\mathrm{R}$ dihedral angle, suggesting that the orbital energies of two $\sigma^{*}(\mathrm{Ch}-\mathrm{Ch})$ change with the $\mathrm{R}-\mathrm{Ch}-\mathrm{Ch}-\mathrm{R}$ dihedral angle. This calculated trend agrees with two empirical rules: the $\mathrm{C}_{2}$ rule and the quadrant rule.
\end{abstract}

\section{Introduction}

The $\mathrm{S}-\mathrm{S}$ bonds in disulfides play an important role in polypeptides, proteins, and other biochemical systems. Spectroscopic observations of several disulfide compounds have been reported, including ultraviolet (UV), ${ }^{1}$ photoelectron, ${ }^{2}$ circular dichroism (CD), ${ }^{1,3}$ nuclear magnetic resonance (NMR), ${ }^{4}$ and electronic diffraction..$^{5}$ Also, a number of calculations for molecular structures, ${ }^{6,7}$ rotational barriers around the $\mathrm{S}-\mathrm{S}$ bonds, ${ }^{8}$ excitation spectra, ${ }^{9}$ optical rotation, ${ }^{10}$ vibrational frequencies, ${ }^{11}$ and NMR spectra ${ }^{5}$ have been carried out with both semiempirical and ab initio quantum-chemical methods. Some of the experimental and theoretical investigations have indicated that the spectroscopic molecular properties of dichalcogens are correlated with the $\mathrm{S}-\mathrm{S}$ dihedral angle. In fact, the optical rotation of molecules containing $\mathrm{R}-\mathrm{Ch}-\mathrm{Ch}-\mathrm{R}$ is theoretically determined by $\sin 2 \theta$, where $\theta$ is the dihedral angle.

Diselenides and ditellurides have properties analogous to those of disulfides, and have also been studied experimentally. ${ }^{1}$ The UV spectra of diselenides and ditellurides have shapes quite similar to those of disulfides, although the absorption bands are red shifted in comparison with those of disulfides. However, no theoretical studies on diselenides and ditellurides have been reported so far except for a series of works by Renugopalakrishnan, Walter, and co-workers. ${ }^{12,13}$ A systematic theoretical study of dichalcogen molecules (chalcogen $=\mathrm{S}, \mathrm{Se}, \mathrm{Te}$ ) is therefore required.

Optical activity is one of the most specific properties of chiral molecules and is determined by optical rotation, Raman optical

* To whom correspondence should be addressed. E-mail: hada@ metro-u.ac.jp. activity (ROA), and $\mathrm{CD}$, vibrational $\mathrm{CD}$ (VCD), and magnetic $\mathrm{CD}$ (MCD) spectra. Optical rotation is the difference in refractive index between left and right circularly polarized light when an optically active molecule is irradiated with linearly polarized light, and $\mathrm{CD}, \mathrm{VCD}$, and $\mathrm{MCD}$ are the differences in absorption intensity between left and right circularly polarized lights. These optical rotation phenomena are related to the absolute configurations of chiral molecules, and ROA, CD, $\mathrm{VCD}$, and MCD give useful information to analyze the spectra of molecules as well. The CD spectra of many disulfide compounds have been reported. ${ }^{1,3}$ Two empirical rules apply to these systems: the $\mathrm{C}_{2}$ rule ${ }^{14,15}$ and the quadrant rule. ${ }^{16}$ The $\mathrm{C}_{2}$ rule determines the plus - minus sign of the $\mathrm{CD}$ absorptions in the longest wavelength region of a chiral $\mathrm{C}_{2}$ symmetrical molecule, whereas the quadrant rule for $\mathrm{C}_{2}$ chromophores determines the relationship between the first and second lowest $\mathrm{CD}$ absorptions; that is, if the $\mathrm{R}-\mathrm{Ch}-\mathrm{Ch}-\mathrm{R}$ dihedral angle is from $0^{\circ}$ to $90^{\circ}$, the lowest excited state belongs to B symmetry and its rotatory strength $(R)$ is positive, and the second lowest excited state belongs to A symmetry and its $R$ is negative. On the other hand, if the $\mathrm{R}-\mathrm{Ch}-\mathrm{Ch}-\mathrm{R}$ dihedral angle is from $90^{\circ}$ to $180^{\circ}$, the lowest excited state belongs to A symmetry and its $R$ is negative, and the second lowest excited state belongs to $\mathrm{B}$ symmetry and its $R$ is positive. These rules have been reproduced by calculations of dihydrogen disulfide. ${ }^{17}$ For diselenides and ditellurides, however, these rules have not yet been investigated.

Certain difficulties exist in assigning the spectral bands in CD. First, the two transition energies are often close to each other. In this case, the two absorptions form one spectral band 
if the $R$ values of those two transitions have the same sign, whereas the band gaps are apparently broadened if the two $R$ values have opposite signs. This makes it difficult to determine the accurate positions of the transitions. Second, the fitting procedures for the $\mathrm{CD}$ spectra are not unique and, therefore, the unique assignment of the CD bands is often difficult. Last, similar to the UV spectra, conventional organic solvents make it difficult to observe the Cotton effect of the target molecules in the short-wavelength region owing to absorption of the solvents. In these cases, careful quantum-chemical calculations may be helpful to analyze unknown or unassigned CD spectra.

The intensity of the CD absorptions is expressed by the rotatory strength $(R)$ of the dipole length representation, which is defined as

$$
R_{\mathrm{ge}}=\operatorname{Im}\left[\left\langle\Psi_{\mathrm{g}}\left|\mu_{\text {ele }}\right| \Psi_{\mathrm{e}}\right\rangle\left\langle\Psi_{\mathrm{e}}\left|\mu_{\mathrm{mag}}\right| \Psi_{\mathrm{g}}\right\rangle\right]
$$

where $\Psi_{\mathrm{g}}$ and $\Psi_{\mathrm{e}}$ are the wave functions of the ground and excited states, respectively, and $\mu_{\text {ele }}$ and $\mu_{\mathrm{mag}}$ are the electronic and magnetic transition dipole moment operators, respectively. So far, many CD calculations have been reported using, for example, classical physics based methods such as the dipole interaction model, ${ }^{18,19}$ semiempirical methods, ${ }^{9,16,20,21}$ random phase approximation (RPA), ${ }^{22-24}$ the time-dependent density functional theory (TDDFT), ${ }^{25-28}$ the independent particle model with the Kohn-Sham theory, ${ }^{29}$ the coupled cluster linear response theory (CCLRT), ${ }^{30,31}$ and the single-excitation configuration interaction (SECI) and single- and double-excitation configuration interaction (SDCI) theory. ${ }^{17,32-35}$ These methods reproduce experimental spectra qualitatively; however, the agreement of the calculated transition energies with the experimental ones is not satisfactory. In some cases, even the signs of the CD strength are opposite those determined experimentally. To make a reliable theoretical assignment, one should use a more sophisticated theory than the previous ones, which takes electron correlation into consideration.

Symmetry adapted cluster $(\mathrm{SAC})^{36}$ and SAC-configuration interaction $(\mathrm{SAC}-\mathrm{CI})^{37}$ methods are an electron-correlation theory that can calculate both ground and excited states, respectively, with well-balanced accuracy. Many applications of this theory to the ground and excited states of various systems have been reported. ${ }^{38-40}$ Since eq 1 requires the wave functions of the ground and excited states, the combination of the SAC and SAC-CI methods is very suitable for CD calculations.

In this study, we calculated the excitation and CD spectra of 12 right-handed dichalcogen compounds with the SAC and SAC-CI methods. The target molecules were dihydrogen dichalcogenide (DHC), dimethyl dichalcogenide (DMC), (+)bis(2-methylbutyl) dichalcogenide (BMC), and 2,3-( $R, R)$-dichalcogenadecalin (DCD). Three kinds of chalcogen atoms (S, Se, and $\mathrm{Te}$ ) were adopted, and the molecular structures are shown in Figure 1a. The objectives of this study were as follows: (1) to compare the excitation and $\mathrm{CD}$ spectra calculated with the SAC and SAC-CI methods with the experimental ones from ref 1 and discuss the accuracy of the calculated results, (2) to assign each band of these molecules, and (3) to examine the dependences of the spectral trends on the type of chalcogen atom. The details of the calculation methods are described in section 2. We present the excitation and CD spectra of the 12 dichalcogen molecules in section 3 and discuss the results in detail in section 4. A conclusion is given in section 5 .

\section{Computational Details}

All ground-state geometries were optimized by MP2 using LanL2DZ ${ }^{41,42}$ with polarization functions. ${ }^{43}$ LanL2DZ consists of the Huzinaga/Dunning full double- $\zeta$ basis set ${ }^{44}$ for the valence shells and the Los Alamos effective core potentials with relativistic effects for the core shells. We carried out geometry optimization of all molecules from all possible initial geometries with $C_{1}$ symmetry, and these geometries were converged to $C_{2}$ symmetry.

The excitation energies, oscillator strengths, and $R$ were calculated with the SAC and SAC-CI methods. The ground states were calculated with the SAC method, and the excited states were calculated with the SAC-CI method using SD (single and double) reference configurations. The lowest five excitations were calculated for each symmetry. The energy thresholds in the configuration selection scheme ${ }^{45}$ were $10^{-6}$ and $10^{-7}$ hartree for the ground and excited states, respectively, except for the ground states of DCD $(\mathrm{Ch}=\mathrm{S}, \mathrm{Se})$, where the thresholds were $7.0 \times 10^{-7}$ hartree. The basis sets for the $\mathrm{Ch}$ atoms in the SAC and SAC-CI calculations were the uncontracted LanL2DZ augmented by the split polarization functions ([2p2d], where $\alpha_{\mathrm{p}}=0.0659,0.0260$ and $\alpha_{\mathrm{d}}=0.9424,0.3720$ for $S ; \alpha_{p}=0.0623,0.0246$ and $\alpha_{d}=0.6897,0.2723$ for Se; $\alpha_{p}$ $=0.0521,0.0206$ and $\alpha_{\mathrm{d}}=0.4750,0.1875$ for Te, respectively) and the Rydberg functions ([1s1p], where $\alpha_{\mathrm{s}}=0.023$ and $\alpha_{\mathrm{p}}$ $=0.020$ for $S ;$ [ $1 \mathrm{~s}]$ where $\alpha_{\mathrm{s}}=0.049$ and $\alpha_{\mathrm{s}}=0.038$ for Se and Te, respectively). We employed the aug-cc-pVDZ basis set ${ }^{46}$ for the $\mathrm{C}$ atoms in all the SAC and SAC-CI calculations, instead of using LanL2DZ. For the $\mathrm{H}$ atoms, as well as the $\mathrm{C}$ atoms, we employed the aug-cc-pVDZ basis set for DHC and DMC, and the Huzinaga/Dunning double- $\zeta$ basis set for BDC and DCD, considering accuracy and computational feasibility.

All calculations were carried out using the modified local version of Gaussian $03^{48}$ program package. The $\mathrm{CD}$ spectra were fitted by Gaussian functions for each position of the excitation.

$$
\begin{aligned}
& \Delta \epsilon(\omega)= \frac{16 \pi^{2} N_{\mathrm{A}}}{3000 c \hbar \ln 10} \frac{\omega}{\alpha} \sqrt{\frac{\ln 16}{\pi \omega_{j a}}} \times \\
&=\left(4.0908 \times 10^{38}\right) \sum_{j a} \frac{\omega}{\alpha \sqrt{\omega_{j a}}} \times \\
& \exp \left(-\frac{\ln 16}{\omega_{j a}}\left(\frac{\omega-\omega_{j a}}{\alpha}\right)^{2}\right) R_{j a} \\
& \exp \left(-\frac{\ln 16}{\omega_{j a}}\left(\frac{\omega-\omega_{j a}}{\alpha}\right)^{2}\right) R_{j a}(2)
\end{aligned}
$$

where $\Delta \epsilon$ and $R_{j a}$ are given in $\mathrm{mol}^{-1} \cdot \mathrm{cm}^{-1}$ and esu $\cdot \mathrm{cm} \cdot \mathrm{erg} \cdot \mathrm{G}^{-1}$, respectively, $\omega_{j a}$ and $R_{j a}$ are the excitation energies between $j$ and $a$ and the rotatory strengths, respectively, and $\alpha$ is a fitting parameter taken from the bandwidth of the experimental spectrum.

We used the dipole length representation for calculations of rotatory strengths, and this representation has the gauge origin problem. Therefore, we have confirmed that this problem is small for the molecule we employed.

\section{Results}

Optimized Geometries. We summarize in Table 1 the optimized geometric parameters of the 12 dichalcogen molecules, DHC, DMC, BMC, and DCD. The $\mathrm{S}-\mathrm{S}, \mathrm{Se}-\mathrm{Se}$, and $\mathrm{Te}-\mathrm{Te}$ bond lengths are almost the same for all the molecules, and as expected, the $\mathrm{Ch}-\mathrm{Ch}$ bond lengths follow the order $r_{\mathrm{S}-\mathrm{S}}$ $<r_{\mathrm{Se}-\mathrm{Se}}<r_{\mathrm{Te}-\mathrm{Te}}$. The optimized dihedral angles of $\mathrm{R}-\mathrm{Ch}-$ $\mathrm{Ch}-\mathrm{R}$ in the straight-chain compounds (DHC, DMC, and BMC) 
(a)

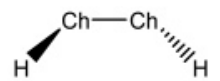

(+)-dihydrogen dichalcogenide (DHC)

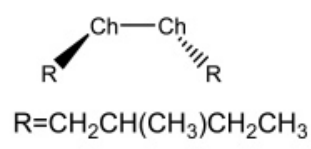

(+)-bis(2-methylbutyl) dichalcogenide (BDC)

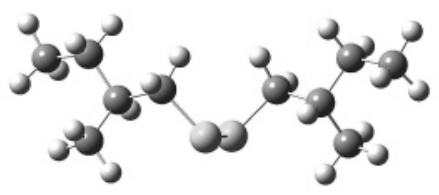

(+)-bis(2-methylbutyl) dichalcogenide (BDC)

(b)

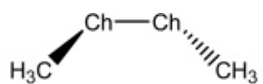

(+)-dimethyl dichalcogenide

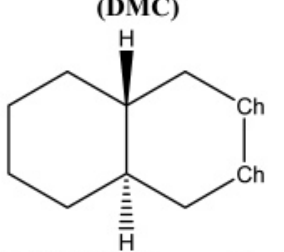

2,3-(R,R)-dichalcogenadecalin (DCD) Figure 1. (a) Structures of 12 right-handed dichalcogen molecules
$(\mathrm{Ch}=\mathrm{S}, \mathrm{Se}, \mathrm{Te})$. (b) Most stable conformation of $(+)$-bis $(2$ methylbutyl) dichalcogneide $(\mathrm{Ch}=\mathrm{S}, \mathrm{Se}, \mathrm{Te})$.

are ca. $90^{\circ}$, whereas the dihedral angles of the cyclic compound (DCD) are ca. $60^{\circ}$. These bond lengths and dihedral angles agree satisfactorily with the experiments and previous calculations. 3,13,20,21,29 As mentioned above, the CD spectra of disulfide compounds strongly depend on the molecular conformations, in particular, the dihedral angles of $\mathrm{R}-\mathrm{Ch}-\mathrm{Ch}-\mathrm{R} .{ }^{17}$ Therefore, it is worthwhile to study the relationship between $R$ and the geometric parameters. This will be discussed later.

Dihydrogen Dichalcogenide (DHC). DHC is a straight-chain molecule as shown in Figure 1, and the rotational energy barriers around the $\mathrm{Ch}-\mathrm{Ch}$ bond are quite small. Therefore, racemization easily occurs between left- and right-handed molecules. Owing to this racemization, the experimental CD spectrum of DHC could not be observed. However, the calculated $R$ values for DHC are useful for comparative study because DHC is the simplest dichalcogen molecule. Moreover, the calculations of DHC have been reported in several theoretical studies. ${ }^{9,20}$

Table 2 lists the excitation energies, oscillator strengths, rotatory strengths, and assignments of DHC for the lowest six singlet transitions calculated with the SAC and SAC-CI methods. In the case of dihydrogen disulfide $(\mathrm{Ch}=\mathrm{S})$, compared with a previous work that used semiempirical CNDO, ${ }^{9}$ the SAC and SAC-CI methods comparatively well reproduced the experimental position of the first lowest peak. In all cases,

the first and second lowest excited states, which are expressed as $2 \mathrm{~A}$ and $1 \mathrm{~B}$, respectively, are almost degenerate energetically, and both states are assigned to the transitions from the two $\mathrm{n}$ chalcogen orbitals to the $\sigma^{*}(\mathrm{Ch}-\mathrm{Ch})$ orbital, namely, $\mathrm{n}-\sigma^{*}$ $(\mathrm{Ch}-\mathrm{Ch})$. The signs of $R$ are negative for the $2 \mathrm{~A}$ state and positive for the 1B state. The third and fourth lowest excited states, which are $2 \mathrm{~B}$ and $3 \mathrm{~A}$, respectively, are also degenerate energetically, and both states are assigned to $n-\sigma^{*}(\mathrm{Ch}-\mathrm{H})$. The signs of $R$ are positive and negative for the 3A and 2B states, respectively, contrary to the lowest two states. The $R$ values of these four low-lying excitations are comparable to each other irrespective of the Ch atoms; e.g., the $R$ values are 15.14, 17.05, and $22.06\left(10^{-40} \mathrm{cgs}\right.$ unit) in the $1 \mathrm{~B}$ state and $65.65,57.51$, and 41.74 in the $3 \mathrm{~A}$ state, when $\mathrm{Ch}=\mathrm{S}, \mathrm{Se}$, and $\mathrm{Te}$, respectively. On the other hand, the excitation energies of the four low-lying states are shifted to the lower energy region when the $\mathrm{Ch}$ atom is replaced with a heavier atom. The fifth and sixth excitations are assigned again to $\mathrm{n}-\sigma^{*}(\mathrm{Ch}-\mathrm{Ch})$, although the signs and values of $R$ largely depend on the chalcogens. Figure 2 shows the calculated excitation energies (left) and $R$ (right). The CD spectra fitted by the Gaussian function in eq 2 are also shown, although the experimental spectra have been not reported. Basically, the spectral shapes of $\mathrm{S}, \mathrm{Se}$, and Te molecules are similar to each other, although a red shift of the spectral bands occurs as the $\mathrm{Ch}$ atom is replaced with a heavier atom, as shown in Table 1.

The empirical $\mathrm{C}_{2}$ rule predicts that, in a right-handed molecule, the lowest excited A state shows the negative Cotton effect whereas the lowest B state shows the positive Cotton effect. $^{14,15}$ The present calculations of $R$ agree with the $\mathrm{C}_{2}$ rule.

Dimethyl Dichalcogenide (DMC). Both excitation and CD spectra of DMC have been studied using several theoretical methods, whereas only the UV spectra obtained experimentally have been reported. The excitation energies, the oscillator strengths, and the rotatory strengths of DMC are shown in Table 3. Our results show good agreement with the experimental ones, compared with the previous work that used the CI method. ${ }^{34}$ There are several analogies between the spectra of DMC and those of DHC. The first and second lowest excited states are assigned to $\mathrm{n}-\sigma^{*}(\mathrm{Ch}-\mathrm{Ch})$. The signs of $R$ are negative and positive for symmetry $\mathrm{A}$ and $\mathrm{B}$ excitations, respectively, showing agreement with the $\mathrm{C}_{2}$ rule. Furthermore, their values are almost constant irrespective of the $\mathrm{Ch}$ atoms. The third and fourth lowest excitations are assigned to the transitions from $\mathrm{n}$ on the $\mathrm{Ch}$ atoms to $\sigma^{*}$ on the $\mathrm{Ch}-\mathrm{C}$ bonds $\left(\mathrm{n}-\sigma^{*}(\mathrm{Ch}-\mathrm{C})\right.$ ). The $R$ values also have the same signs and magnitudes, except for the $3 \mathrm{~A}$ state for dimethyl disulfide $(\mathrm{Ch}=\mathrm{S})$. The $4 \mathrm{~A}$ and

TABLE 1: Geometric Parameters ${ }^{a}$ Optimized by the MP2 Method Using the LanL2DZP Basis Set together with the Experimental Values

\begin{tabular}{clllll}
\hline compound & $\mathrm{Ch}$ & \multicolumn{1}{c}{$r_{\mathrm{Ch}-\mathrm{Ch}}$} & $r_{\mathrm{R}-\mathrm{Ch}}$ & $\theta_{\mathrm{Ch}-\mathrm{Ch}-\mathrm{R}}$ & \multicolumn{1}{c}{$\phi(\mathrm{dihedral})^{b}$} \\
\hline DHC & $\mathrm{S}$ & $2.08(2.055)^{c}$ & $1.36(1.327)^{c}$ & $97.22(91.3)^{c}$ & $91.03(90.06)^{c}$ \\
& $\mathrm{Se}$ & 2.35 & 1.48 & 95.61 & 90.14 \\
& $\mathrm{Te}$ & 2.72 & 1.67 & 95.02 & 89.06 \\
$\mathrm{DMC}$ & $\mathrm{S}$ & $2.07(2.022)^{c}$ & $1.82(1.806)^{c}$ & $101.14(104.1)^{c}$ & $83.97(83.6)^{c}$ \\
& $\mathrm{Se}$ & 2.34 & $1.96(1.954)^{d}$ & $98.80(98.8)^{d}$ & 84.02 \\
& $\mathrm{Te}$ & 2.71 & 2.15 & 97.01 & 85.57 \\
BDC & $\mathrm{S}$ & 2.07 & 1.83 & 100.86 & 84.86 \\
& $\mathrm{Se}$ & 2.34 & 1.97 & 98.19 & 83.64 \\
& $\mathrm{Te}$ & 2.71 & 2.17 & 95.61 & 83.86 \\
$\mathrm{DCD}$ & $\mathrm{S}$ & 2.08 & 1.83 & 97.48 & $58.34(\sim 60.0)^{e}$ \\
& $\mathrm{Se}$ & 2.35 & 1.97 & 93.72 & 55.25 \\
& $\mathrm{Te}$ & 2.72 & 2.17 & 88.83 & 52.11
\end{tabular}

${ }^{a}$ Bond lengths $r$ are given in angstroms, and angles $\theta$ and $\phi$ are given in degrees. ${ }^{b}$ Dihedral angles of $\mathrm{R}-\mathrm{Ch}-\mathrm{Ch}-\mathrm{R}$. ${ }^{c} \mathrm{Values}$ in parentheses are experimental ones from ref $21 .^{d}$ Values in parentheses are experimental ones from ref $13 .{ }^{e}$ Value in parentheses is experimental one from ref 3. 
TABLE 2: Excitation Energies $\Delta E$ in $\mathrm{eV}$, Oscillator Strength $f$ in au, Rotatory Strength $R$ in $10^{-40}$ cgs unit, and Assignment of Transition for (+)-Dihydrogen Dichalcogenide (DHC) $(\mathrm{Ch}=\mathrm{S}$, Se, Te) Calculated with SAC and SAC-CI Methods

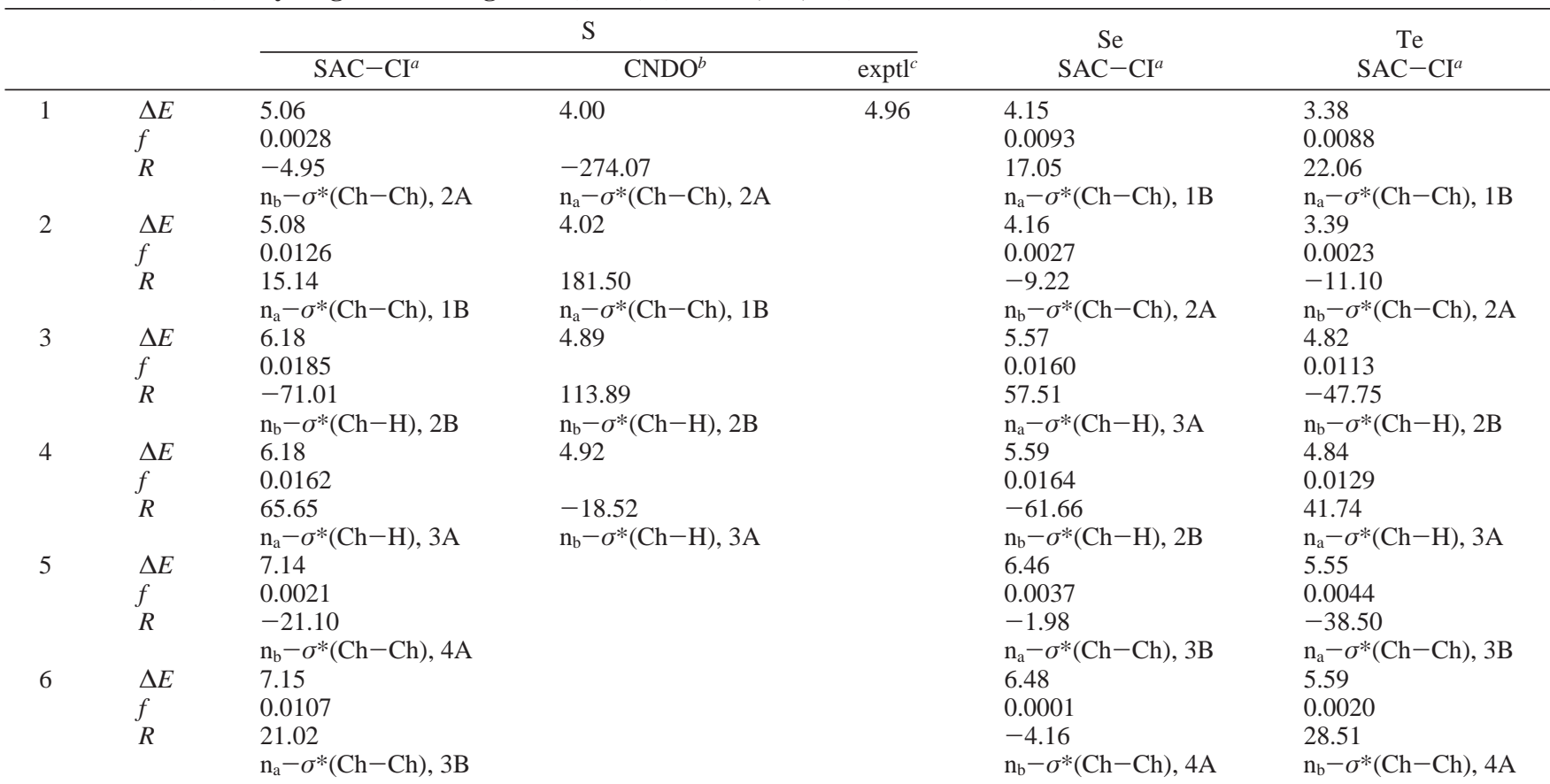

${ }^{a}$ Present work. ${ }^{b}$ Reference 9. ${ }^{c}$ References 21 and 47.

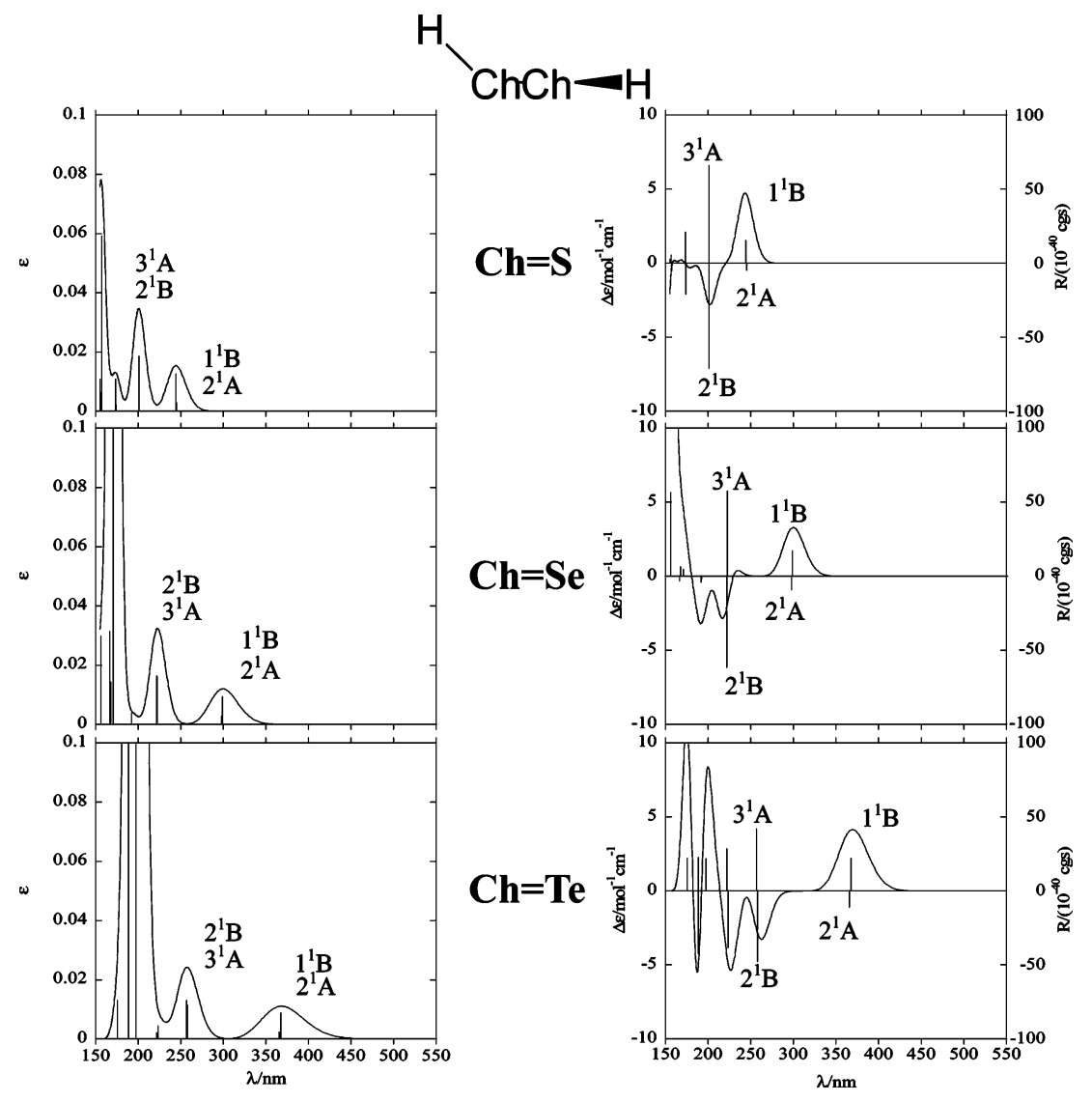

Figure 2. UV (left) and CD (right) spectra calculated with SAC and SAC-CI methods for dihydrogen dichalcogenide (DHC).

$3 \mathrm{~B}$ states are assigned to the $\mathrm{n}-\sigma^{*}(\mathrm{Ch}-\mathrm{C})$ transitions in the case of $\mathrm{Ch}=\mathrm{S}$, and the transitions from $\mathrm{n}$ to Rydberg orbitals on the $\mathrm{Ch}$ atoms in the cases of $\mathrm{Ch}=\mathrm{Se}$ and $\mathrm{Te}$. The excitation energies are red shifted in all cases as the $\mathrm{Ch}$ atoms become heavier. We note here one difference from DHC: The energy differences between the first and second lowest excitations are much larger in DMC than in DHC. The energy differences are $0.21,0.20$, and $0.13 \mathrm{eV}$ when $\mathrm{Ch}=\mathrm{S}, \mathrm{Se}$, and Te, respectively, whereas they are almost zero for DHC.

On the left side of Figure 3, the observed and calculated excitation spectra of DMC are drawn for each dichalcogenide. The energy positions of the calculated bands are in good 
TABLE 3: Excitation Energies $\Delta E$ in $\mathrm{eV}$, Oscillator Strength $f$ in au, Rotatory Strength $R$ in $10^{-40}$ cgs unit, and Assignment of Transition for (+)-Dimethyl Dichalcogenide (DMC) $(\mathrm{Ch}=\mathrm{S}$, Se, Te) Calculated with SAC and SAC-CI Methods

\begin{tabular}{|c|c|c|c|c|c|c|c|c|}
\hline & & \multicolumn{3}{|c|}{$\mathrm{S}$} & \multicolumn{2}{|l|}{$\mathrm{Se}$} & \multicolumn{2}{|l|}{$\mathrm{Te}$} \\
\hline & & $\mathrm{SAC}-\mathrm{CI}^{a}$ & $\mathrm{CI}^{b}$ & $\overline{\operatorname{exptl}{ }^{c}}$ & $\mathrm{SAC}-\mathrm{CI}^{a}$ & $\overline{\operatorname{exptl}^{c}}$ & $\mathrm{SAC}-\mathrm{CI}^{a}$ & $\overline{\text { exptl }^{c}}$ \\
\hline \multirow[t]{4}{*}{1} & $\Delta E$ & 4.85 & 5.93 & 4.96 & 3.96 & 3.96 & 3.23 & 3.06 \\
\hline & $f$ & 0.0140 & 0.0160 & & 0.0079 & & 0.0071 & \\
\hline & $R$ & 23.22 & 27.40 & & 21.76 & & 27.48 & \\
\hline & & $\mathrm{n}_{\mathrm{a}}-\sigma^{*}(\mathrm{Ch}-\mathrm{Ch}), 1 \mathrm{~B}$ & $\mathrm{n}_{\mathrm{a}}-\sigma^{*}(\mathrm{Ch}-\mathrm{Ch}), 1 \mathrm{~B}$ & & $\mathrm{n}_{\mathrm{a}}-\sigma^{*}(\mathrm{Ch}-\mathrm{Ch}), 1 \mathrm{~B}$ & & $\mathrm{n}_{\mathrm{a}}-\sigma^{*}(\mathrm{Ch}-\mathrm{Ch}), 1 \mathrm{~B}$ & \\
\hline \multirow{4}{*}{2} & $\Delta E$ & 5.06 & 6.23 & & 4.16 & & 3.36 & \\
\hline & $f$ & 0.0011 & 0.0067 & & 0.0013 & & 0.0010 & \\
\hline & $R$ & -6.35 & -26.40 & & -10.17 & & -11.39 & \\
\hline & & $\mathrm{n}_{\mathrm{b}}-\sigma^{*}(\mathrm{Ch}-\mathrm{Ch}), 2 \mathrm{~A}$ & $\mathrm{n}_{\mathrm{b}}-\sigma^{*}(\mathrm{Ch}-\mathrm{Ch}), 2 \mathrm{~A}$ & & $\mathrm{n}_{\mathrm{b}}-\sigma^{*}(\mathrm{Ch}-\mathrm{Ch}), 2 \mathrm{~A}$ & & $\mathrm{n}_{\mathrm{b}}-\sigma^{*}(\mathrm{Ch}-\mathrm{Ch}), 2 \mathrm{~A}$ & \\
\hline \multirow[t]{4}{*}{3} & $\Delta E$ & 6.04 & 7.66 & & 5.50 & & 4.60 & \\
\hline & $f$ & 0.0071 & 0.0110 & & 0.0002 & & 0.0011 & \\
\hline & $R$ & 9.76 & -34.60 & & -2.07 & & -5.49 & \\
\hline & & $\mathrm{n}_{\mathrm{a}}-\sigma^{*}(\mathrm{Ch}-\mathrm{C}), 3 \mathrm{~A}$ & $2 \mathrm{~B}$ & & $\mathrm{n}_{\mathrm{a}}-\sigma^{*}(\mathrm{Ch}-\mathrm{C}), 3 \mathrm{~A}$ & & $\mathrm{n}_{\mathrm{a}}-\sigma^{*}(\mathrm{Ch}-\mathrm{C}), 3 \mathrm{~A}$ & \\
\hline \multirow[t]{4}{*}{4} & $\Delta E$ & 6.20 & 7.75 & & 5.52 & & 4.59 & \\
\hline & $f$ & 0.0039 & 0.0040 & & 0.0029 & & 0.0034 & \\
\hline & $R$ & -28.29 & 13.00 & & -19.85 & & -34.56 & \\
\hline & & $\mathrm{n}_{\mathrm{b}}-\sigma^{*}(\mathrm{Ch}-\mathrm{C}), 2 \mathrm{~B}$ & $3 \mathrm{~A}$ & & $\mathrm{n}_{\mathrm{a}}-\sigma^{*}(\mathrm{Ch}-\mathrm{C}), 2 \mathrm{~B}$ & & $\mathrm{n}_{\mathrm{a}}-\sigma^{*}(\mathrm{Ch}-\mathrm{C}), 2 \mathrm{~B}$ & \\
\hline \multirow[t]{4}{*}{5} & $\Delta E$ & 6.24 & & & 5.69 & & 5.20 & \\
\hline & $f$ & 0.0064 & & & 0.0281 & & 0.0221 & \\
\hline & $R$ & 27.60 & & & 56.39 & & 54.18 & \\
\hline & & $\mathrm{n}_{\mathrm{a}}-\sigma^{*}(\mathrm{Ch}-\mathrm{C}), 4 \mathrm{~A}$ & & & $\mathrm{n}_{\mathrm{a}}-\mathrm{s}, 4 \mathrm{~A}$ & & $\mathrm{n}_{\mathrm{b}}-\mathrm{s}, 3 \mathrm{~B}$ & \\
\hline \multirow[t]{4}{*}{6} & $\Delta E$ & 6.37 & & & 5.89 & & 5.21 & \\
\hline & $f$ & 0.0452 & & & 0.0504 & & 0.0546 & \\
\hline & $R$ & -26.89 & & & -53.81 & & 86.51 & \\
\hline & & $\mathrm{n}_{\mathrm{b}}-\sigma^{*}(\mathrm{Ch}-\mathrm{C}), 3 \mathrm{~B}$ & & & $\mathrm{n}_{\mathrm{b}}-\mathrm{p}, 3 \mathrm{~B}$ & & $\mathrm{n}_{\mathrm{a}}-\mathrm{p}, 4 \mathrm{~A}$ & \\
\hline
\end{tabular}

${ }^{a}$ Present work. ${ }^{b}$ Reference $34 .{ }^{c}$ Reference 1 .

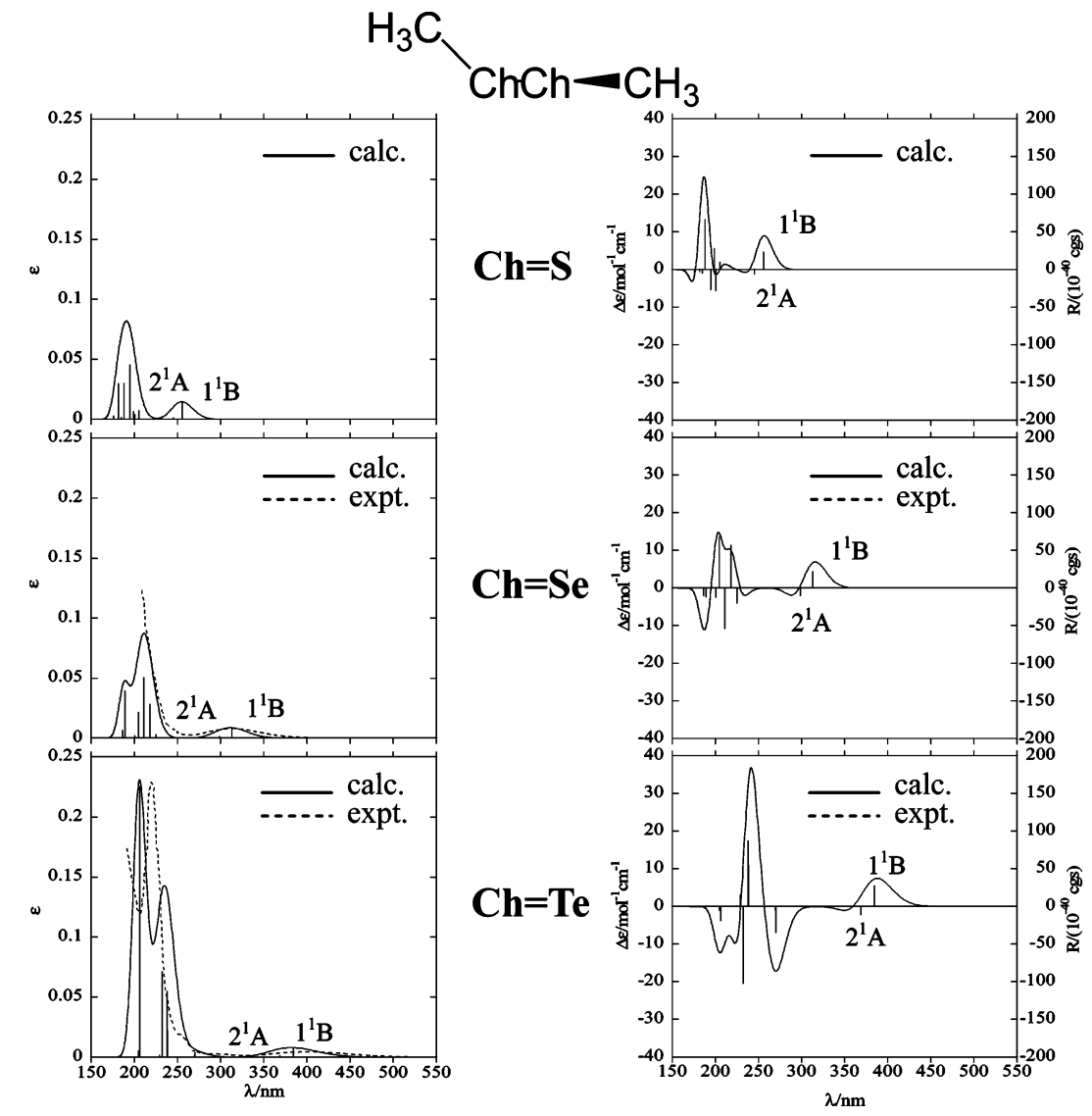

Figure 3. SAC and SAC-CI calculated and observed ${ }^{1}$ UV (left) and CD (right) spectra for dimethyl dichalcogenide (DMC).

agreement with the experimental ones. The intensity of the second lowest peak is much higher than that of the first lowest peak, in accordance with the experimental trends. Thus, the calculated results well reproduce the experimental spectra. The right side of Figure 3 shows the calculated CD spectra of DMC. The spectral shapes are similar among the chalcogenides, although the intensities in the short-wavelength region are increased as the $\mathrm{Ch}$ atoms become heavier. One can also see 
TABLE 4: Excitation Energies $\Delta E$ in eV, Oscillator Strength $f$ in au, Rotatory Strength $R$ in $10^{-40}$ cgs unit, and Assignment of Transition for 2,3-(R,R)-Dichalcogenadecalin $(\mathrm{DCD})(\mathrm{Ch}=\mathrm{S}$, Se, Te) Calculated with SAC and SAC-CI Methods

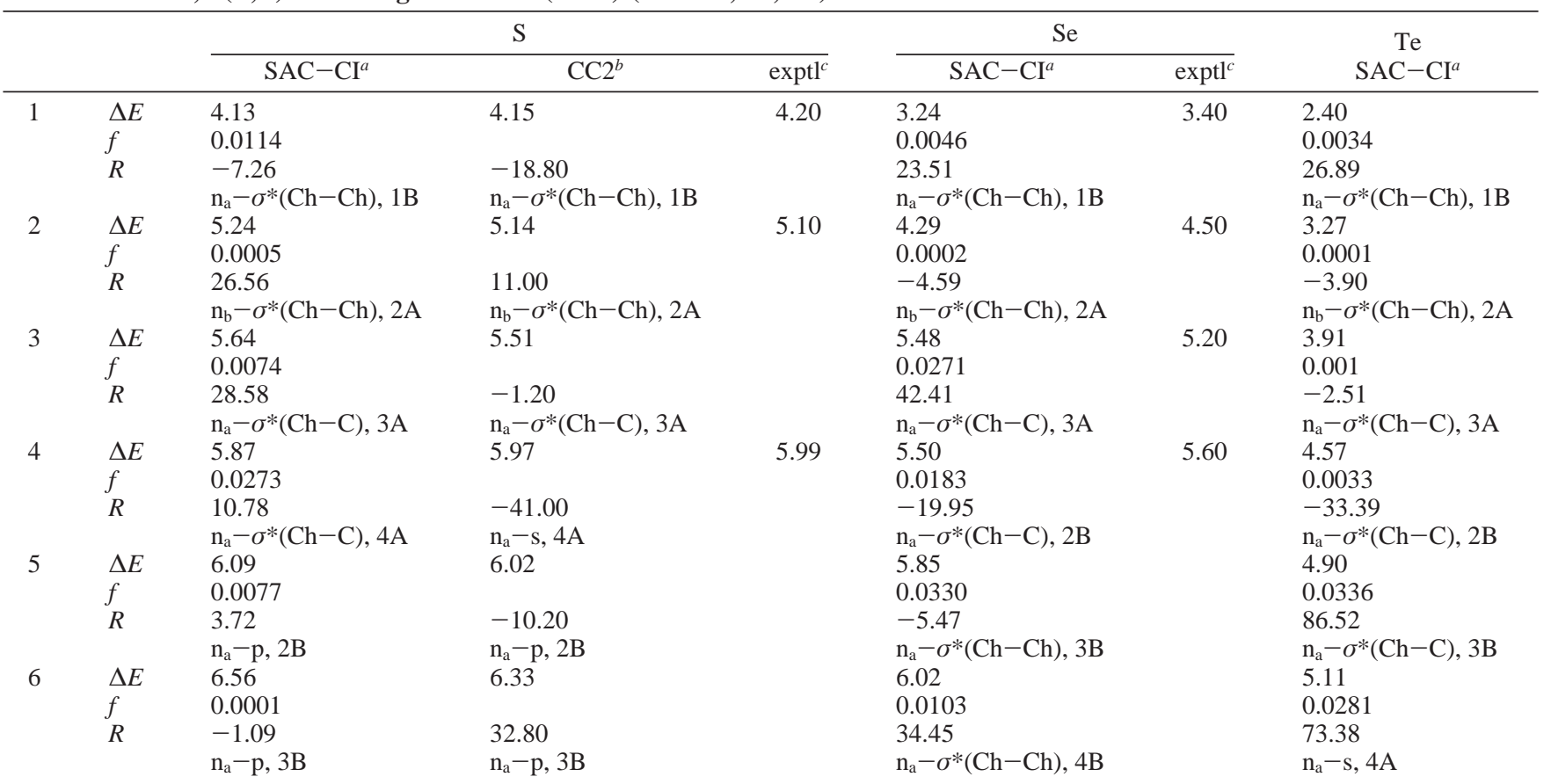

${ }^{a}$ Present work. ${ }^{b}$ Reference $25 .{ }^{c}$ Reference 1.

the energy shifts of the peaks depending on the Ch atoms in the long-wavelength region in the excitation and CD spectra, in accordance with experimental trends.

2,3-( $R, \boldsymbol{R})$-Dichalcogenadecalin (DCD). DCD is a typical and simple cyclic dichalcogen compound whose UV and CD spectra have been measured experimentally. 2,3-( $S, S)$-dithiadecalin has been studied by several quantum-chemical methods $;{ }^{25}$ however, it should be noted that we adopted here a series of enantiomers, 2,3-(R,R)-dichalcogenadecalins, for comparison with each other. The CD spectra of these right-handed molecules have the same intensities as those of the left-handed 2,3-(S,S)-dichalcogenadecalin, but opposite signs.

The calculated results are listed in Table 4. The excitation energies of 2,3-(S,S)-dithiadecalin are similar to those of the previous coupled cluster calculation including single and approximate double excitations (CC2), although the $R$ values and their assignments are different. The SAC-CI excitation energies for dithiadecalin and diselenadecalin are similar to the experimental values in all cases, suggesting that our calculations are reliable. DCD also shows analogous trends to DMC concerning the assignments, the signs and magnitudes of $R$, and the energy shift due to the change of $\mathrm{Ch}$ atoms; that is, the first and second lowest excited states (1B and $2 \mathrm{~A}$ ) are assigned to $\mathrm{n}-\sigma^{*}(\mathrm{Ch}-\mathrm{Ch})$, and the third and fourth lowest ones (3A and 2B) are assigned to $\mathrm{n}-\sigma^{*}(\mathrm{Ch}-\mathrm{C})$. The signs and magnitudes of $R$ for the lowest two excitations (1B and 2A) are the same among $\mathrm{S}$, Se, and Te compounds, showing applicability of the $\mathrm{C}_{2}$ rule. The red shift due to heavy $\mathrm{Ch}$ atoms is also observed in DCD. One unique feature in DCD is that the energy differences between the first and second lowest excited states (1B and 2A) are relatively large in comparison with those of straight-chain compounds. The calculated energy differences are $1.11,1.05$, and $0.87 \mathrm{eV}$ when $\mathrm{Ch}=\mathrm{S}, \mathrm{Se}$, and Te, respectively. These values well reproduce the experimental values, 0.9 and $1.1 \mathrm{eV}$, in the cases of $\mathrm{Ch}=\mathrm{S}$ and $\mathrm{Se}$, respectively. On the left side of Figure 4, the experimental and theoretical excitation spectra are depicted. The calculated spectra well reproduce the experimental spectral shapes, and the excitation energy differences are less than $0.3 \mathrm{eV}$. The second lowest peak of the experimental UV spectra consists of three or more excitations. The right side of Figure 4 shows the calculated CD spectra and the corresponding experimental spectra. The calculated results show good agreement with the experiment for each molecule, suggesting that the assignments by the present calculations are highly reliable.

(+)-Bis(2-methylbutyl) Dichalcogenide (BDC). Generally, it is expected that some acyclic compounds have many conformations that are almost degenerate in energy. Therefore, we carried out geometry optimization of BDC from all possible initial conformations using the MP2/LanL2DZP method. As a result, we determined the most stable conformation as shown in Figure 1b, whose energy is lower by $5 \mathrm{~kJ} / \mathrm{mol}$ or more compared with the other conformations. Then, considering the thermal population, the lowest conformation is dominant. Therefore, we calculated only the most stable conformations for BDC.

The calculated results are listed in Table 5. The low-lying $1 \mathrm{~B}$ and $2 \mathrm{~A}$ states are assigned to the $\mathrm{n}-\sigma^{*}(\mathrm{Ch}-\mathrm{Ch})$ transitions, and the $3 \mathrm{~A}$ and $2 \mathrm{~B}$ states are assigned to $\mathrm{n}-\sigma^{*}(\mathrm{Ch}-\mathrm{C})$, except for the case of $\mathrm{Ch}=\mathrm{S}$. The $4 \mathrm{~A}$ and $3 \mathrm{~B}$ states are assigned to the transitions from $n$ to various characters, due to the large mixing between $\sigma^{*}$ and Rydberg orbitals. The signs and magnitudes of $R$ for the lowest two states are consistent with the $\mathrm{C}_{2}$ rule, irrespective of the $\mathrm{Ch}$ atoms. The energy red shift as $\mathrm{Ch}$ becomes heavier was also calculated. The energy differences of BDC between $1 \mathrm{~B}$ and $2 \mathrm{~A}$ excited states are 0.26 , 0.28 , and $0.20 \mathrm{eV}$ when $\mathrm{Ch}=\mathrm{S}, \mathrm{Se}$, and Te, respectively. These values have the same magnitude as those of DMC, although they are somewhat underestimated compared with the experimental values. Comparing BDC with DMC, the magnitudes and signs of the $R$ values of the third and fourth lowest excitations for BDC are different from those for DMC, probably because the $\sigma^{*}(\mathrm{Ch}-\mathrm{C})$ orbital is largely sensitive to the substituted group. 


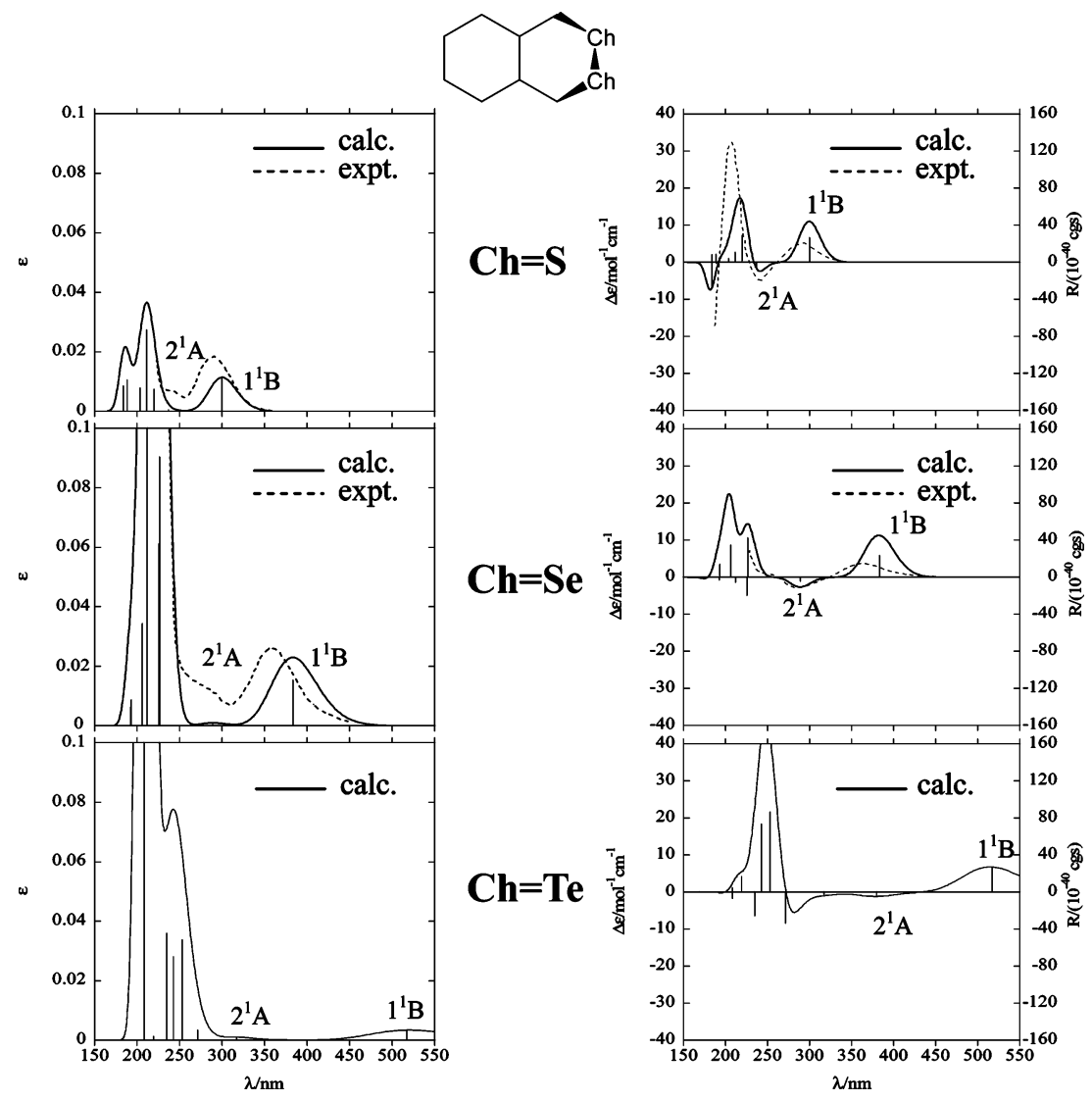

Figure 4. SAC and SAC-CI calculated and observed ${ }^{1} \mathrm{UV}$ (left) and CD (right) spectra for 2,3-(R,R)-dichalcogenadecalin (DCD).

TABLE 5: Excitation Energies $\Delta E$ in $\mathrm{eV}$, Oscillator Strength $f$ in au, Rotatory Strength $R$ in $10^{-40}$ cgs unit, and Assignment of Transition for (+)-Bis(2-methylbutyl) Dichalcogenide (BDC) $(\mathrm{Ch}=\mathrm{S}$, Se, Te) Calculated with SAC and SAC-CI Methods

\begin{tabular}{|c|c|c|c|c|c|c|c|}
\hline & & \multicolumn{2}{|l|}{$S$} & \multicolumn{2}{|l|}{$\mathrm{Se}$} & \multicolumn{2}{|l|}{$\mathrm{Te}$} \\
\hline & & $\mathrm{SAC}-\mathrm{CI}^{a}$ & $\operatorname{exptl}^{b}$ & $\mathrm{SAC}-\mathrm{CI}^{a}$ & $\operatorname{exptl}^{b}$ & $\mathrm{SAC}-\mathrm{CI}^{a}$ & $\operatorname{exptl}^{b}$ \\
\hline \multirow[t]{4}{*}{1} & $\Delta E$ & 4.38 & 4.60 & 3.54 & 3.60 & 2.90 & 3.05 \\
\hline & $f$ & 0.0176 & & 0.0095 & & 0.0078 & \\
\hline & $R$ & 19.16 & & 18.77 & & 24.70 & \\
\hline & & $\mathrm{n}_{\mathrm{a}}-\sigma^{*}(\mathrm{Ch}-\mathrm{Ch}), 1 \mathrm{~B}$ & & $\mathrm{n}_{\mathrm{a}}-\sigma^{*}(\mathrm{Ch}-\mathrm{Ch}), 1 \mathrm{~B}$ & & $\mathrm{n}_{\mathrm{a}}-\sigma^{*}(\mathrm{Ch}-\mathrm{Ch}), 1 \mathrm{~B}$ & \\
\hline \multirow[t]{4}{*}{2} & $\Delta E$ & 4.64 & 5.20 & 3.82 & 4.30 & 3.10 & 3.42 \\
\hline & $f$ & 0.0007 & & 0.0008 & & 0.0008 & \\
\hline & $R$ & -3.92 & & -6.16 & & -7.23 & \\
\hline & & $\mathrm{n}_{\mathrm{b}}-\sigma^{*}(\mathrm{Ch}-\mathrm{Ch}), 2 \mathrm{~A}$ & & $\mathrm{n}_{\mathrm{b}}-\sigma^{*}(\mathrm{Ch}-\mathrm{Ch}), 2 \mathrm{~A}$ & & $\mathrm{n}_{\mathrm{b}}-\sigma^{*}(\mathrm{Ch}-\mathrm{Ch}), 2 \mathrm{~A}$ & \\
\hline \multirow[t]{4}{*}{3} & $\Delta E$ & 5.66 & & 5.29 & & 4.46 & 4.64 \\
\hline & $f$ & 0.0005 & & 0.0015 & & 0.0000 & \\
\hline & $R$ & 1.96 & & 11.47 & & -0.62 & \\
\hline & & $\mathrm{n}_{\mathrm{a}}-\sigma^{*}(\mathrm{Ch}-\mathrm{C}), 3 \mathrm{~A}$ & & $\mathrm{n}_{\mathrm{a}}-\sigma^{*}(\mathrm{Ch}-\mathrm{C}), 3 \mathrm{~A}$ & & $\mathrm{n}_{\mathrm{a}}-\sigma^{*}(\mathrm{Ch}-\mathrm{C}), 3 \mathrm{~A}$ & \\
\hline \multirow[t]{4}{*}{4} & $\Delta E$ & 5.77 & & 5.40 & & 4.52 & 4.66 \\
\hline & $\bar{f}$ & 0.0034 & & 0.0005 & & 0.0003 & \\
\hline & $R$ & 17.06 & & 3.78 & & -6.05 & \\
\hline & & $\mathrm{n}_{\mathrm{a}}-\mathrm{p}, 4 \mathrm{~A}$ & & $\mathrm{n}_{\mathrm{b}}-\sigma^{*}(\mathrm{Ch}-\mathrm{C}), 2 \mathrm{~B}$ & & $\mathrm{n}_{\mathrm{a}}-\sigma^{*}(\mathrm{Ch}-\mathrm{C}), 2 \mathrm{~B}$ & \\
\hline \multirow[t]{4}{*}{5} & $\Delta E$ & 5.86 & & 5.58 & & 5.02 & \\
\hline & $f$ & 0.0142 & & 0.0109 & & 0.0072 & \\
\hline & $R$ & -11.22 & & 30.46 & & 38.82 & \\
\hline & & $\mathrm{n}_{\mathrm{a}}-\mathrm{s}, 2 \mathrm{~B}$ & & $\mathrm{n}_{\mathrm{a}}-\sigma^{*}(\mathrm{Ch}-\mathrm{Ch}), 4 \mathrm{~A}$ & & $\mathrm{n}_{\mathrm{b}}-\sigma^{*}(\mathrm{Ch}-\mathrm{C}), 3 \mathrm{~B}$ & \\
\hline \multirow[t]{4}{*}{6} & $\Delta E$ & 6.04 & & 5.73 & 5.70 & 5.16 & \\
\hline & $f$ & 0.0028 & & 0.0231 & & 0.0000 & \\
\hline & $R$ & -10.34 & & -40.29 & & -1.63 & \\
\hline & & $\mathrm{n}_{\mathrm{b}}-\sigma^{*}(\mathrm{Ch}-\mathrm{C}), 3 \mathrm{~B}$ & & $\mathrm{n}_{\mathrm{b}}-\sigma^{*}(\mathrm{Ch}-\mathrm{C}), 3 \mathrm{~B}$ & & $\mathrm{n}_{\mathrm{b}}-\sigma^{*}(\mathrm{Ch}-\mathrm{C}), 4 \mathrm{~A}$ & \\
\hline
\end{tabular}

${ }^{a}$ Present work. ${ }^{b}$ Reference 1 .

The excitation spectra (left) and CD spectra (right), which are observed and fitted with calculated results, are plotted in Figure 5. The fitted excitation spectra show good agreement with the observed ones, although underestimations of the band energies are found. The calculated CD spectra also reproduce well the experimental ones on the whole, although some band intensities are overestimated compared with the experimental ones. On the other hand, the energy differences of the first and second lowest states are small and the $R$ values show opposite signs; as a result, these band positions seem to be shifted owing 


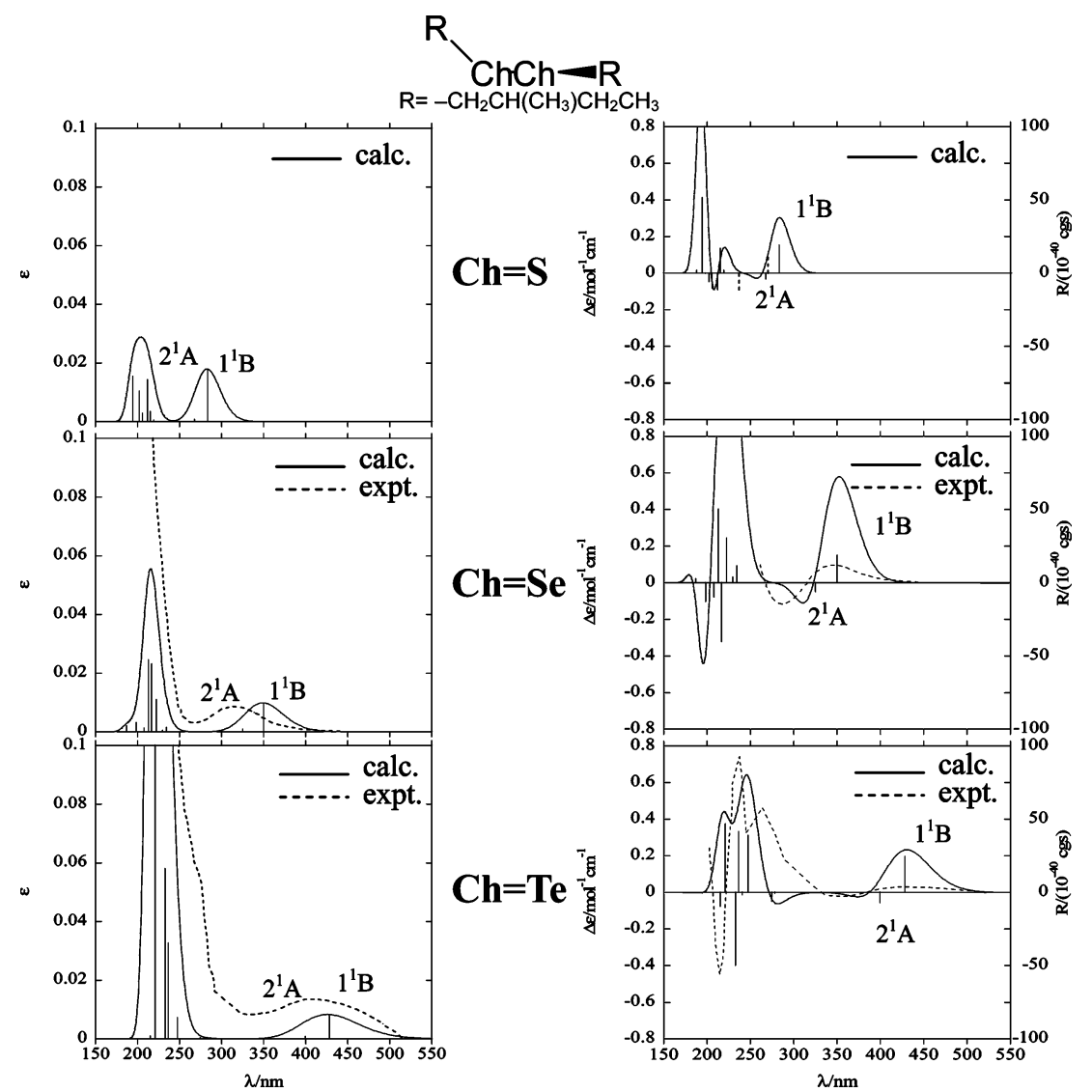

Figure 5. SAC and SAC-CI calculated and observed ${ }^{1} \mathrm{UV}$ (left) and CD (right) spectra for (+)-bis(2-methylbutyl) dichalcogenide (BDC).

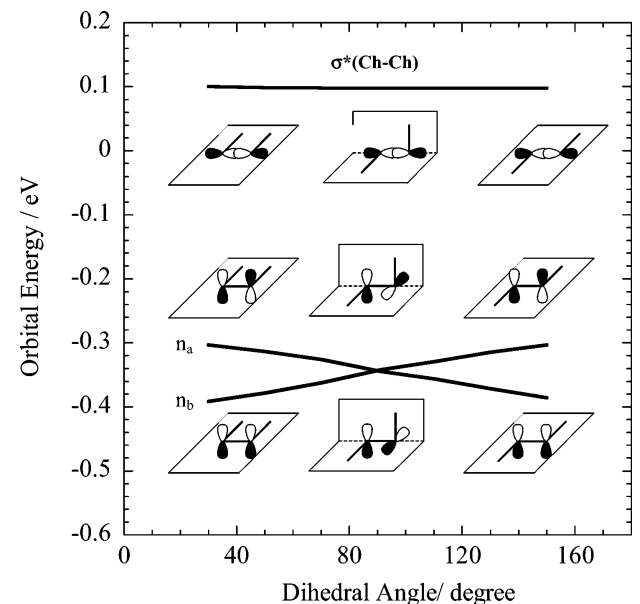

Figure 6. HOMO and LUMO for dihydrogen disulfide calculated with MP2/LanL2DZP as functions of the $\mathrm{Ch}-\mathrm{Ch}$ dihedral angle.

to cancellation of their intensities. The results indicate that we should be careful in determining the accurate positions of excitations in the experimental CD spectra.

\section{Discussion}

Using quantum-chemical methods, we have shown that the CD spectra of disulfides, diselenides, and ditellurides depend on the molecular geometries, especially the dihedral angle about the $\mathrm{Ch}-\mathrm{Ch}$ bonds $\left(\phi_{\mathrm{R}-\mathrm{Ch}-\mathrm{Ch}-\mathrm{R}}\right)$. This phenomenon is analyzed in terms of the molecular orbitals (MOs). Figure 6 shows the relationship between $\phi_{\mathrm{R}-\mathrm{Ch}-\mathrm{Ch}-\mathrm{R}}$ and the MO energies associated with the $\mathrm{n}-\sigma^{*}(\mathrm{Ch}-\mathrm{Ch})$ transitions of dihydrogen disulfide. Since the highest occupied molecular orbital (HOMO) and the next HOMO are two n orbitals and the lowest unoccupied molecular orbital (LUMO) is a $\sigma^{*}(\mathrm{Ch}-\mathrm{Ch})$ orbital in $\mathrm{S}$, Se, and Te molecules, this figure can be applied to all the molecules treated. When $\phi_{\mathrm{R}-\mathrm{Ch}-\mathrm{Ch}-\mathrm{R}}$ is varied from $0^{\circ}$ to $180^{\circ}$, the energy of the $n$ orbital of symmetry $b\left(n_{b}\right)$ is increased because the overlap between the electron lobes of the two $\mathrm{Ch}$ atoms becomes large. By contrast, for the $n$ orbital of symmetry a $\left(n_{a}\right)$, the MO energy is decreased because repulsion between the lobes becomes large as $\phi_{\mathrm{R}-\mathrm{Ch}-\mathrm{Ch}-\mathrm{R}}$ is increased. When $\phi_{\mathrm{R}-\mathrm{Ch}-\mathrm{Ch}-\mathrm{R}}$ is $90^{\circ}$, the energies of the two $\mathrm{n}$ orbitals are degenerate. On the other hand, the $\sigma^{*}$ orbital energy is almost constant irrespective

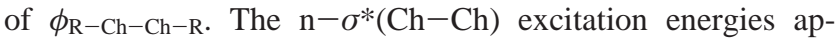
proximately correspond to the energy differences between the $\mathrm{n}$ and $\sigma^{*}$ orbitals. When $\phi_{\mathrm{R}-\mathrm{Ch}-\mathrm{Ch}-\mathrm{R}}$ is less than $90^{\circ}$, the first lowest excitation is assigned to $\mathrm{n}_{\mathrm{a}}-\sigma^{*}(\mathrm{Ch}-\mathrm{Ch})$ and the second is assigned to $\mathrm{n}_{\mathrm{b}}-\sigma^{*}(\mathrm{Ch}-\mathrm{Ch})$. This leads to the negative Cotton effect. By contrast, when $\phi_{\mathrm{R}-\mathrm{Ch}-\mathrm{Ch}-\mathrm{R}}$ is greater than $90^{\circ}$, the first and second lowest excitations are assigned to $\mathrm{n}_{\mathrm{b}}-\sigma^{*}(\mathrm{Ch}-$ $\mathrm{Ch})$ and $\mathrm{n}_{\mathrm{a}}-\sigma^{*}(\mathrm{Ch}-\mathrm{Ch})$, respectively, giving the positive Cotton effect. When $\phi_{\mathrm{R}-\mathrm{Ch}-\mathrm{Ch}-\mathrm{R}}$ is nearly $90^{\circ}$, the two $\mathrm{n}-\sigma^{*}(\mathrm{Ch}-\mathrm{Ch})$ excitations are degenerate and the negative and positive contributions of the two states cancel each other. Consequently, the CD intensity becomes nearly zero. These trends are called the quadrant rule. ${ }^{16}$

Table 6 shows the dihedral angles about the $\mathrm{Ch}-\mathrm{Ch}$ bonds,

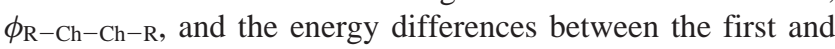
second lowest excitations calculated with SAC and SAC-CI methods for the 12 dichalcogen molecules. The experimental values of the energy differences between the first and second lowest bands are also listed in this table. Table 6 indicates that the results of the energy differences agree with the quadrant rule. For DHC, $\phi_{\mathrm{R}-\mathrm{Ch}-\mathrm{Ch}-\mathrm{R}}$ is nearly $90^{\circ}$ irrespective of the $\mathrm{Ch}$ atoms, and the first and second lowest excitations are almost degenerate. The signs of the $R$ values are opposite, accounting 
TABLE 6: Dihedral Angles about the $\mathrm{Ch}-\mathrm{Ch}$ Bonds and Energy Differences between the First and Second Lowest Excitations

\begin{tabular}{|c|c|c|c|c|}
\hline \multirow[b]{2}{*}{ molecule } & \multirow[b]{2}{*}{$\mathrm{Ch}$} & \multirow{2}{*}{$\begin{array}{l}\text { dihedral angle }^{a} \\
\text { (deg) }\end{array}$} & \multicolumn{2}{|c|}{ energy difference $(\mathrm{eV})$} \\
\hline & & & calcd $^{a}$ & $\operatorname{exptl}^{b}$ \\
\hline \multirow[t]{3}{*}{ DHC } & $\mathrm{S}$ & 91.03 & 0.02 & \\
\hline & $\mathrm{Se}$ & 90.14 & 0.01 & \\
\hline & $\mathrm{Te}$ & 89.06 & 0.01 & \\
\hline \multirow[t]{3}{*}{ DMC } & $\mathrm{S}$ & 83.97 & 0.21 & \\
\hline & $\mathrm{Se}$ & 84.02 & 0.22 & \\
\hline & $\mathrm{Te}$ & 85.57 & 0.13 & \\
\hline \multirow[t]{3}{*}{ DCD } & $\mathrm{S}$ & 58.34 & 1.11 & 0.9 \\
\hline & $\mathrm{Se}$ & 55.25 & 1.05 & 1.1 \\
\hline & $\mathrm{Te}$ & 52.11 & 0.87 & \\
\hline \multirow[t]{3}{*}{$\mathrm{BDC}$} & $\mathrm{S}$ & 84.86 & 0.26 & 0.6 \\
\hline & $\mathrm{Se}$ & 83.64 & 0.28 & 0.7 \\
\hline & $\mathrm{Te}$ & 83.86 & 0.20 & 0.7 \\
\hline
\end{tabular}

${ }^{a}$ Present work. ${ }^{b}$ Reference 1.

for the very low CD intensities. The calculated energy differences of these states are $0.2-0.3 \mathrm{eV}$ for DMC and BDC with $\phi_{\mathrm{R}-\mathrm{Ch}-\mathrm{Ch}-\mathrm{R}} \approx 85^{\circ}$, while they are ca. $1.0 \mathrm{eV}$ for $\mathrm{DCD}$ with $\phi_{\mathrm{R}-\mathrm{Ch}-\mathrm{Ch}-\mathrm{R}} \approx 55^{\circ}$. This shows that the energy difference between the first and second lowest excitations becomes large as $\phi_{\mathrm{R}-\mathrm{Ch}-\mathrm{Ch}-\mathrm{R}}$ deviates from $90^{\circ}$, in accordance with the quadrant rule.

Our calculations demonstrated that the excitation energies are red shifted in all cases as the $\mathrm{Ch}$ atom is replaced with a heavier atom. This is consistent with the trends found in the experiments for DMC, DCD, and BDC. We believe that this can be explained as follows. In the low-energy region, many excitations are associated with the n orbital, which is a bonding orbital, and the $\mathrm{n}$ orbital is dominated by each $\mathrm{Ch}$ atom. As the $\mathrm{Ch}$ atom is heavier, the electron density is more spread around the $\mathrm{Ch}$ atom. As a result, the $\mathrm{n}$ orbital is less stable and the related excitation energy is lower. We see this trend for all the calculated compounds; for example, the $\mathrm{n}$ orbital energies of $\mathrm{DHC}$ are $-0.383,-0.359$, and -0.326 au when $\mathrm{Ch}=\mathrm{S}$, Se, and Te, respectively. Both solvent and relativistic effects are not directly considered in the present study. The experimental spectra are generally measured in solvents, and in particular, CD spectra can be influenced by solvent effects because CD is very sensitive to the molecular geometry. For ditelluride, relativistic effects are expected to be important, and the contribution of triplet excitations through spin-orbit terms should be considered. Further investigations using more accurate calculations that take these effects into consideration need to be conducted in the future.

\section{Conclusion}

The excitation energies and the rotatory strengths were calculated with the SAC and SAC-CI methods for 12 dichalcogen molecules, DHC, DMC, DCD, and BDC, and their excitation and CD spectra were simulated. The calculated spectra were compared with the experimental ones, and the spectral dependences on the molecular conformations and the chalcogen atoms were investigated. Through these calculations, we make the following conclusions.

(1) The excitation and CD spectra calculated with SAC and $\mathrm{SAC}-\mathrm{CI}$ methods were in good agreement with the experiments in the present molecules.

(2) The differences in CD spectra among cyclic and acyclic dichalcogens could be explained in terms of the relationship between the dihedral angles and the molecular orbital energies.

(3) As the $\mathrm{Ch}$ atom was replaced with a heavier atom, the bands were shifted to the lower energy region in all cases.
(4) The calculated results agreed with the empirical rules such as the $\mathrm{C}_{2}$ rule and the quadrant rule for all the molecules investigated.

Acknowledgment. We are grateful to Professor P. H. A. Laur for experimental UV and CD spectra. This work was supported by a Grant-in-Aid for Scientific Research from the Ministry of Education, Culture, Sports, Science and Technology of Japan.

\section{References and Notes}

(1) Laur, P. H. A. In Proceedings of the Third International Symposium on Organic Selenium and Tellurium Compounds; Cagniant, D., Kirsch, G., Eds.; Universite de Metz: Metz, 1979; pp 219-299.

(2) Carles, S.; Lecomte, F.; Schermann, J. P.; Desfrançois, C.; Xu, S.; Nilles, J. M.; Bowen, K. M.; Berges, J.; Houee-Levin, C. J. Phys. Chem. A 2001, 105, 5622 .

(3) Neubert, L. A.; Carmack, M. J. Am. Chem. Soc. 1974, 96, 943.

(4) Jiao, D.; Barfield, M.; Combariza, J. E.; Hruby, V. J. J. Am. Chem. Soc. 1992, 114, 3639 .

(5) Beagley, B.; McAloon, K. T. Trans. Faraday Soc. 1971, 67, 3216.

(6) Ohsaku, M.; Allinger, N. L. J. Phys. Chem. 1988, 92, 4591.

(7) Steudel, R. Angew. Chem., Int. Ed. Engl. 1975, 14, 655.

(8) Boyd, D. B. J. Am. Chem. Soc. 1972, 94, 8799.

(9) Webb, J.; Strickland, R. W.; Richardson, F. S. J. Am. Chem. Soc. 1973, 95, 4775.

(10) Polavarapu, P. L.; Chakraborty, D. K.; Ruud, K. Chem. Phys. Lett. 2000, 319, 595. 6891 .

(11) Zhao, W.; Bandekar, J.; Krimm, S. J. Am. Chem. Soc. 1988, 110,

(12) Renugopalakrishnan, V.; Wyssbrod, H. R.; Walter, R.; Druyan, M. E. J. Chem. Phys. 1982, 77, 1362.

(13) Renugopalakrishnan, V.; Walter, R. J. Am. Chem. Soc. 1984, 106, 3413 .

(14) Wagniere, G.; Hug, W. Tetrahedron Lett. 1970, 55, 4765.

(15) Hug, W.; Wagniere, G. Tetrahedron 1972, 28, 1241.

(16) Linderberg, J.; Michl, J. J. Am. Chem. Soc. 1970, 92, 2619.

(17) Ha, T. K.; Cencek, W. Chem. Phys. Lett. 1991, 182, 519.

(18) Carlson, K. L.; Lowe, S. L.; Hoffmann, M. R.; Thomasson, K. A. J. Phys. Chem. A 2005, 109, 5463.

(19) Hirst, J. D.; Colella, K.; Gilbert, A. T. B. J. Phys. Chem. B 2003 $107,11813$.

(20) Gould, R. R.; Hoffmann, R. J. Am. Chem. Soc. 1970, 92, 1813.

(21) Snyder, J. P.; Carlsen, L. J. Am. Chem. Soc. 1977, 99, 2931.

(22) Uray, G.; Verdino, P.; Belaj, F.; Kappe, C. O.; Fabian, W. M. F. J. Org. Chem. 2001, 66, 6685.

(23) Pedersen, T. B.; Hansen, A. E. Chem. Phys. Lett. 1995, 246, 1.

(24) Hansen, A. E.; Bouman, T. D. J. Am. Chem. Soc. 1985, 107, 4828.

(25) Diedrich, C.; Grimme, S. J. Phys. Chem. A 2003, 107, 2524

(26) Guennic, B. L.; Hieringer, W.; Görling, A.; Autschbach, J. J. Phys. Chem. A 2005, 109, 4836.

(27) Autschbach, J.; Ziegler, T.; Gisbergen, S. J. A.; Baerends, E. J. J. Chem. Phys. 2002, 116, 6930.

(28) Autschbach, J.; Jorge, F. E.; Ziegler, T. Inorg. Chem. 2003, 42, 2867.

(29) Bour, P. J. Phys. Chem. A 1999, 103, 5099.

(30) Pedersen, T. B.; Koch, H.; Ruud, K. J. Chem. Phys. 1999, 110 2883.

(31) Pedersen, T. B.; Koch, H. J. Chem. Phys. 2000, 112, 2139.

(32) Shustov, G. V.; Kachanov, A. V.; Korneev, V. A., Kostyanovsky,

R. G.; Rauk, A. J. Am. Chem. Soc. 1993, 115, 10267.

(33) Shustov, G. V.; Kadorkina, G. K.; Kostyanovsky, R. G.; Rauk, A.

J. Am. Chem. Soc. 1988, 110, 1719.

(34) Rauk, A. J. Am. Chem. Soc. 1984, 106, 6517

(35) Rauk, A. J. Am. Chem. Soc. 1981, 103, 1023.

(36) Nakatsuji, H.; Hirao, K. J. Chem. Phys. 1978, 68, 2053.

(37) (a) Nakatsuji, H. Chem. Phys. Lett. 1978, 59, 362. (b) Nakatsuji, H. Chem. Phys. Lett. 1979, 67, 329.

(38) Nakatsuji, H. In Computational Chemistry, Reviews of Current Trends; Leszczynski, J., Ed.; World Scientific: Singapore, 1997; Vol. 2.

(39) Hasegawa, J.; Nakatsuji, H. Chem. Lett. 2005, 34, 1242.

(40) Hasegawa, J.; Takata, K.; Miyahara, T.; Neya, S.; Frisch, M. J.; Nakatsuji, H. J. Phys. Chem. A 2005, 109, 3187.

(41) Hay, P. J.; Wadt, W. R. J. Chem. Phys. 1985, 82, 270.

(42) Hay, P. J.; Wadt, W. R. J. Chem. Phys. 1985, 82, 299.

(43) Check, C. E.; Faust, T. O.; Bailey, J. M.; Wright, B. J.; Gilbert, T. M.; Sunderlin, L. S. J. Phys. Chem. A 2001, 105, 8111.

(44) (a) Dunning, T. H., Jr. J. Chem. Phys. 1970, 53, 2823. (b) Dunning, T. H., Jr.; Hay, P. J. In Methods of Electronic Structure Theory; Schaefer, H. F., III, Ed.; Plenum Press: New York, 1977; Vol. 3. 
(45) (a) Nakatsuji, H. Chem. Phys. 1983, 75, 425. (b) Nakatsuji, H.; Hasegawa, J.; Hada, M. J. Chem. Phys. 1996, 104, 2321. (c) Tokita, Y.; Hasegawa, J.; Nakatsuji, H. J. Phys. Chem. A 1998, 102, 1843.

(46) Dunning, T. H., Jr. J. Chem. Phys. 1989, 90, 1007.

(47) Feher, F.; Münzner, H. Chem. Ber. 1963, 96, 1131

(48) Frisch, M. J.; Trucks, G. W.; Schlegel, H. B.; Scuseria, G. E.; Robb, M. A.; Cheeseman, J. R.; Montgomery, J. A., Jr.; Vreven, T.; Kudin, K. N.; Burant, J. C.; Millam, J. M.; Iyengar, S. S.; Tomasi, J.; Barone, V.; Mennucci, B.; Cossi, M.; Scalmani, G.; Rega, N.; Petersson, G. A.; Nakatsuji, H.; Hada, M.; Ehara, M.; Toyota, K.; Fukuda, R.; Hasegawa, J.; Ishida, M.; Nakajima, T.; Honda, Y.; Kitao, O.; Nakai, H.; Klene, M.; Li,
X.; Knox, J. E.; Hratchian, H. P.; Cross, J. B.; Adamo, C.; Jaramillo, J.; Gomperts, R.; Stratmann, R. E.; Yazyev, O.; Austin, A. J.; Cammi, R.; Pomelli, C.; Ochterski, J. W.; Ayala, P. Y.; Morokuma, K.; Voth, G. A.; Salvador, P.; Dannenberg, J. J.; Zakrzewski, V. G.; Dapprich, S.; Daniels, A. D.; Strain, M. C.; Farkas, O.; Malick, D. K.; Rabuck, A. D Raghavachari, K.; Foresman, J. B.; Ortiz, J. V.; Cui, Q.; Baboul, A. G.; Clifford, S.; Cioslowski, J.; Stefanov, B. B.; Liu, G.; Liashenko, A.; Piskorz, P.; Komaromi, I.; Martin, R. L.; Fox, D. J.; Keith, T.; Al-Laham, M. A.; Peng, C. Y.; Nanayakkara, A.; Challacombe, M.; Gill, P. M. W.; Johnson, B.; Chen, W.; Wong, M. W.; Gonzalez, C.; Pople, J. A. Gaussian03, revision A.1; Gaussian, Inc.: Pittsburgh, PA, 2003. 